\title{
ASPECTOS EPIDEMIOLÓGICOS DAS VÍTIMAS DE AGRESSÕES FíSICAS ATENDIDAS EM UM PRONTO SOCORRO DO MUNICÍPIO DE SÃO PAULO.
}

\author{
Eliane Côrrea Chaves* \\ Angela Maria Geraldo Pierin* \\ Cilene Aparecida Costardi Ide* \\ Katia Grillo Padilha*
}

\begin{abstract}
RESUMO - Apresenta um levantamento feito num Pronto Socorro, da incidência das lesões decorrentes de agressões físicas, a proporção de óbitos e a média de permanência de internação. Ficou evidenciado que o maior número de danos são causados por arma de fogo e arma branca, a incidência de óbitos é de $10,9 \%$ e 3,9\%, respectivamente, e a média de permanência da maioria dos casos é de até cinco dias.
\end{abstract}

\begin{abstract}
It presents a survey carried out at an Emergency Hospital, on the incidence of lesions resulting from physical aggression, the diath rate and the patient average permanence in the hospital. It has become evident that most injuries are caused by firearms and cutting weapons, the death incidences are those of $10.9 \%$ and $3.9 \%$, respectively, and the average of hospital permanence in most cases is of up to five days.
\end{abstract}

\section{INTRODUC̣ÃO}

Sabe-se que a incidência de agressões dos mais variados tipos tem aumentado, significativamente, sobretudo nos centros urbanos. A grande São Paulo, pela sua própria abrangência populacional, congregando pessoas de diversas partes do país, sem dispor de estrutura adequada para integrá-las satisfatoriamente no seu contexto social, tem se deparado constantemente com o problema da violência e suas conseqüências.

Dentre elas, as lesões físicas decorrentes de agressões por arma de fogo, arma branca, estupro, espancamento, briga, entre outras, surgem, normalmente, de maneira inesperada e súbita, determinando, do ponto de vista clínico, uma situação emergencial que freqüentemente culmina com o atendimento a nível de Pronto Socorro.

IDE et alii (1986) numa tentativa de dimensionar aspectos dessa problemática, realizaram um estudo no
Pronto Socorro do Instituto Central do Hospital das Clínicas da Faculdade de Medicina da USP (PS IC HC FM USP), constatando que, do total de internações ocorridas em 13 meses, $12,5 \%$ deles decorreram de agressões físicas.

Sendo assim, torna-se imprescindível que os profissionais de saúde envolvidos com $o$ atendimento de emergência investiguem os aspectos epidemiológicos dessas agressões de maneira a fundamentar cientificamente a assistência a ser prestada às vítimas, além de nortear o ensino e a pesquisa.

Segundo PETLUND (1980), o estudo da mortalidade e morbidade das diversas doenças pode apresentar algumas distorções quando desenvolvidas a nível de hospital em função dos casos que ocorrem sem envolver estas instituições. Por outro lado, o estudo de outras características como o sexo, a idade, o tipo de agressão, a permanência e a evolução são passíveis de análise, sobretudo a esse nível, uma vez que o atendimento

\footnotetext{
* Enfermeiras, Professoras Assistentes da Disciplina Enfermagem Médico-Cirúrgica da Escola de Enfermagem da USP.
} 
hospitalar implica em registro e evolução dos acontecimentos.

Acredita-se que para $o$ aluno de enfermagem, a unidade de Pronto Socorro pode propiciar, no decorrer de sua formação, grande diversidade de experiências em função da variedade de situações que ali se apresentam, em particular as agressões, como também of erecer oportunidades de execução de uma série de atividades psicomotoras. Com base nessas consideraçêos, nos parece procedente 0 interesse em desenvolver um trabalho que possibilite a caracterização e análise de duas situações fundamentais para o ensino de enfermagem: o perfil epidemiológico das agressões e sua inserção no contexto geral de um Pronto Socorro. Para tanto, são os seguintes os objetivos desta investigação: - pesquisar, entre as vítimas, o tipo de agressão sofri$\mathrm{da}$, a proporção de óbitos em relação à sobrevida e a média de duração das internações;

- investigar a possível associação entre estas variáveis com o sexo e a idade.

\section{METODOLOGIA}

O estudo foi baseado em levantamento retrospectivo de dados obtidos pela Divisão de Arquivo Médico do Hospital das Clínicas da Faculdade de Medicina da Universidade de São Paulo - (HCFMUSP). A população foi constituída pela totalidade das vítimas de agressão internadas no Pronto Socorro deste hospital no período de janeiro de 1984 a janeiro de 1985 .

\subsection{Classificação do tipo de agressão}

No agrupamento dos tipos de violência sof rida pela população deste estudo foi utilizada a categorização preconizada pela Divisão de Arquivo Médico do HCFMUSP que por sua vez baseia-se na Classificação
Internacional Estatística de doenças, lesões e causas de óbito.

Abrangeu-se agressões decorrentes da utilização de instrumentos como arma de fogo e branca além daquelas caracterizadas por espancamento, estupro e mordedura por outra pessoa.

\subsection{Tratamento estatístico}

Os dados foram analisados em índices absolutos e percentuais.

\section{RESULTADOS E DISCUSSÃO}

Antecedendo a análise dos dados, julga-se necessário enfocar sua relatividade. 0 contingente aqui obtido pode representar uma parcela de um grupo maior, porém desconhecido. Na verdade, essa população foi constituída por aqueles que foram suficientemente agredidos que necessitaram, compulsoriamente, de atendimento hospitalar. Uma parcela, cujo ãmbito empiricamente é considerado grande, porém com limites ainda não mensurados, deve existir. Seria representado por aqueles agredidos por formas de violência cuja constatação implicaria em problemas de ordem moral ou social, tais como estupros e espancamentos, e que incorreriam numa nova violência à pessoa quando levados a público e caracterizados legalmente. Tais barreiras já seriam suficientes para a sua não constatação bem como para a não procura da assistência hospitalar.

A partir dessa consideração, serão apresentados e analisados os recursos obtidos, com base em tabelas formuladas a partir de índices absolutos e percentuais.

\subsection{Caracterização da população}

A distribuição do grupo foi elaborada a partir das variáveis biológicas sexo e idade.

TABELA 1 - Distribuição da população, segundo o sexo e a idade, PS IC HC FM USP, 01/1984. a 01/1985.

\begin{tabular}{c|rrrrrrr}
\hline \multirow{2}{*}{ Sexo } & \multicolumn{2}{|c}{ Masculino } & \multicolumn{2}{c}{ Feminino } & \multicolumn{3}{c}{ Total } \\
& No & Node & No & $\%$ & No & \% \\
\hline $0 \vdash 15$ & 24 & $(3,2)$ & 6 & $(9,7)$ & 30 & $(3,7)$ \\
$16 \vdash 30$ & 384 & $(51,2)$ & 26 & $(41,9)$ & 410 & $(50,5)$ \\
$31 \vdash 45$ & 147 & $(19,6)$ & 10 & $(16,1)$ & 157 & $(19,3)$ \\
$46 \vdash 60$ & 43 & $(5,7)$ & 2 & $(3,2)$ & 45 & $(5,6)$ \\
$61 \vdash$ & 4 & $(0,5)$ & - & $(0,0)$ & 4 & $(0,5)$ \\
náo há dados & 148 & $(19,8)$ & 18 & $(29,1)$ & 166 & $(20,4)$ \\
\hline TOTAL & 750 & $(100,0)$ & 62 & $(100,0)$ & & 812 & $(100,0)$ \\
\hline
\end{tabular}


Esses dados tornam patente a predominância dessa forma de violência sobre a população masculina provavelmente ainda mais exposta a tais riscos, quer em situações de trabalho e lazer, quer em convivência, estímulo e perpetuação de atos de tal natureza. Contudo, dentre eles, existe uma maior freqüência de vítimas entre os homens de 16 a 30 anos de idade $(51,2 \%)$. Tal fato pode retratar outra justificativa para esse resultado, ou seja, o aproveitamento desse contingente de pessoas como promotores de violência, caracterizando, agora, não somente a condição de vítima como também a de agressor.

\subsection{Caracterização das formas de violência utilizadas}

Nesse item serão abordadas as agressões sofridas a partir das variáveis sexo e idade.

TABELA 2 - Distribuição da população segundo sexo e tipo de agressão. PS IC HC FMUSP, (01/1984 a (01/1985.

\begin{tabular}{|c|c|c|c|c|c|c|}
\hline \multirow[t]{2}{*}{ Sexo } & \multicolumn{2}{|c|}{ Masculino } & \multicolumn{2}{|c|}{ Feminino } & \multicolumn{2}{|c|}{ Total } \\
\hline & No & $\%$ & № & $\%$ & No & $\%$ \\
\hline arma de fogo & 485 & $(64,7)$ & 39 & $(62,9)$ & 524 & $(64,5)$ \\
\hline arma branca & 214 & $(28,5)$ & 18 & $(29,0)$ & 232 & $(28,6)$ \\
\hline não especificado & 49 & $(6,5)$ & 3 & $(4,8)$ & 52 & $(6,4)$ \\
\hline outros* & 2 & $(0,3)$ & 2 & $(3,2)$ & 4 & $(0,5)$ \\
\hline TOTAL & 750 & $(100,0)$ & 62 & $(100,0)$ & 812 & $(100,0)$ \\
\hline
\end{tabular}

${ }^{*}$ outros: espancamentos, estupro, mordedura por outra pessoa.

Nas diferentes formas de agressão utilizada contra a população deste estudo houve o predomínio da arma de fogo $(64,5 \%)$ seguido pela arma branca $(28,6 \%)$. Essa situação é constante em ambos os sexos e poderia retratar a intencionalidade da agressão uma vez que a arma de fogo configura um instrumento formal de uso para ataque, defesa ou proteção. Por outro lado, cabe ressaltar a falta de controle na liberação e porte de tais armas, caracterizando o grupo armado que traz em si próprio a perpetuação da violência, independente do seu caráter defensivo ou agressor.

TABELA :3 - I)istribuição da população, segundo a idade e tipo de agressão sofrida. PS IC HC FMUSP ()1/1984 a ()1/1985).

\begin{tabular}{|c|c|c|c|c|c|c|c|c|c|c|}
\hline \multirow{2}{*}{ Idade Tipo } & \multicolumn{2}{|c|}{ arma de fogo } & \multicolumn{2}{|c|}{ arma branca } & \multicolumn{2}{|c|}{ não especificado } & \multicolumn{2}{|c|}{ outros* } & \multicolumn{2}{|c|}{ Total } \\
\hline & No & $\%$ & № & $\%$ & No & $\%$ & No & $\%$ & No & $\%$ \\
\hline$\vdash 15$ & 26 & $(86,7)$ & 3 & $(10,0)$ & - & $(0,0)$ & 1 & $(3,3)$ & 30 & $(100,0)$ \\
\hline$\vdash 30$ & 290 & $(70,7)$ & 105 & $(25,6)$ & 15 & $(3,7)$ & - & $(0,0)$ & 410 & $(100,0)$ \\
\hline$\vdash 45$ & 88 & $(56,0)$ & 54 & $(34,4)$ & 13 & $(8,3)$ & 2 & $(1,3)$ & 157 & $(100,0)$ \\
\hline$\vdash 60$ & 21 & $(46,7)$ & 16 & $(35,5)$ & 8 & $(17,8)$ & - & $(0,0)$ & 45 & $(100,0)$ \\
\hline não há dados & 97 & $(58,4)$ & 53 & $(31,9)$ & 15 & $(9,0)$ & 1 & $(0,7)$ & 166 & $(100,0)$ \\
\hline TOTAL & 524 & $(64,5)$ & 232 & $(28,6)$ & 52 & $(6,4)$ & 4 & $(0,5)$ & 812 & $(100,0)$ \\
\hline
\end{tabular}

*outros: espancamento, estupro, mordedura por outra pessoa.

A faixa etária mais vitimada foi a compreendida entre os 16 e 45 anos, o que pode ser justificado pelo fato de ser a mais ativa e exposta, tanto no âmbito de trabalho quanto no social.
Ao se verificar a distribuição dos tipos de agressão nos diferentes grupos etários, observou-se que, embora a agressão por arma de fogo tenha predominado no geral, ela foi a mais freqüente principalmente na po- 
pulação com até 30 anos, sendo que a população mais jovem (até 15 anos) foi a que mais esteve envolvida com essa forma de violência, utilizando a arma de fogo como instrumento de ataque e defesa.

Esses dados parecem retratar ainda mais a problemática de uma significativa parcela de menores que não dispõem de acesso a uma infra-estrutura social que contribua para a formação de uma personalidade íntegra, induzindo-o, pela omissão, cada vez mais a envolver-se em situações de marginilidade.

Essa realidade tende a se agravar paulatinamente uma vez que inexiste uma política de reestruturação social com justa distribuição de recursos materiais possibilitando a transformação desse contexto.

\subsection{Caracterização da evolução}

Na análise do atendimento às vítimas de agressões, cabe ressaltar que a função básica de um Pronto Socorro é atendimento emergencial, isto é, aquele que visa salvaguardar a vida das pessoas. Nesse sentido, espera-se que a população aí atendida tenha uma continuidade de assistência em outras unidades médicas, uma vez que o Pronto Atendimento não tem caráter resolutivo (MENDES, 1982).
O PS IC HC FMUSP, no entanto, não apresenta características típicas desse padrão assistencial na medida em que engloba na sua estrutura unidades especializadas e de retaguarda. Esta infra-estrutura possibilitaria uma permanência mais prolongada, viabilizando um atendimento mais conclusivo. A especificidade desta unidade foi retratada neste estudo uma vez que $55,4 \%$ do grupo permaneceu na mesma até 5 dias, período ainda compatível com os objetivos estabelecidos para esse tipo de atendimento, enquanto que, um contingente também significativo da população $(44,6 \%)$ permaneceu internada por mais de 6 dias, configurando um desvio da proposta de atendimento. Tal fato parece ter sido possível pela existência da infra-estrutura acima referida.

Quanto ao destino desses pacientes, convém salientar que $81,4 \%$ das vítimas permaneceram com tratamento e evolução "em aberto", tendo sido transferidas para outras unidades hospitalares. Esse fato, se numa primeira instãncia é compatível com os objetivos de um serviço emergencial, posteriormente dificulta a análise mais ampla do caráter evolutivo dos envolvidos, na medida em que os resultados relativos à cura e óbito são inconclusivos, retratando o aspecto parcial do atendimento.

TABELA 4 - Distribuição da população segundo o tipo de agressão, a evolução e a média de tempo de permanência. PS IC HC FMUSP, ()1/1984 a ()1/1985.).

\begin{tabular}{|c|c|c|c|c|c|c|c|c|c|c|c|c|c|c|c|c|c|c|}
\hline \multirow{3}{*}{$\begin{array}{l}\text { média de } \\
\text { permanência }\end{array}$} & \multicolumn{6}{|c|}{ arma de fogo } & \multirow{2}{*}{\multicolumn{2}{|c|}{ sub-total }} & \multicolumn{6}{|c|}{ arma branca } & \multicolumn{2}{|c|}{ sub-total } & \multicolumn{2}{|c|}{ Total } \\
\hline & \multicolumn{2}{|c|}{ em evolução } & \multicolumn{2}{|c|}{ curado } & \multicolumn{2}{|c|}{ óbito } & & & \multicolumn{2}{|c|}{ em evolução } & \multicolumn{2}{|c|}{ curado } & \multicolumn{2}{|c|}{ óbito } & \multirow[b]{2}{*}{ No } & \multirow[b]{2}{*}{$\%$} & \multirow[b]{2}{*}{ N? } & \multirow[b]{2}{*}{$\%$} \\
\hline & № & $\%$ & No & $\%$ & No & $\%$ & № & $\%$ & № & $\%$ & No & $\%$ & No & $\%$ & & & & \\
\hline $0 \vdash 5$ & 209 & $(77,1)$ & 18 & $(6,7)$ & 44 & $(16,2)$ & 271 & $(100,0)$ & 109 & $(8: 3,8)$ & $1: 3$ & $(10,0)$ & 8 & $(6,0)$ & 130 & $(100,0)$ & 401 & $(5: 3,5)$ \\
\hline $6 \vdash 15$ & 151 & $(83,9)$ & 20) & $(11,1)$ & 9 & $(5,0)$ & 180 & $(100,(0)$ & 58 & $(78,4)$ & 15 & $(20,3)$ & 1 & $(1,3)$ & 74 & $(100,0)$ & 254 & $(33,9)$ \\
\hline $16 \vdash 16$ & 60 & $(85,7)$ & 6 & $(8,6)$ & 4 & $(5,7)$ & 70 & $(100,0)$ & 22 & $(91,7)$ & 2 & $(8,3)$ & - & $(0,0)$ & 24 & $(100,0)$ & 94 & $(12,6)$ \\
\hline TOTAL & 420 & $(80,7)$ & 44 & $(8,4)$ & 57 & $(10,9)$ & 521 & $(100,0)$ & 189 & $(82,8)$ & 30 & $(13,1)$ & 9 & $(3,9)$ & 228 & $(100,0)$ & 749 & $(100,0)$ \\
\hline
\end{tabular}

${ }^{*}$ Foram retirados deste total outros tipos de agressões.

Pelos dados da Tabela 4, pode-se observar que entre os feridos por arma de fogo, os óbitos $(10,9 \%)$ foram mais freqüentes do que a cura $(8,4 \%)$. Entre as vítimas de arma branca ocorreu o inverso, sendo que a cura aconteceu em 13,1\% e o óbito em 3,9\%. A comparação evolutiva entre os dois tipos de agressão parece retratar o predomínio do óbito precoce entre as vítimas de arma de fogo $(16,2 \%)$ sobre os demais feridos $(6,0 \%)$. Mais uma vez, cabe considerar a relatividade desses resultados, pois a maioria da população dos dois grupos encontra-se com o prognóstico em aberto $(80,7 \%$ e $82,8 \%$, respectivamente).
Esse perfil de evolução retratando, comparativamente, maior freqüência de óbitos e menor proporção de cura entre os agredidos por armas de fogo pode estar relacionado às características de lesão determinados por esse instrumento de violência. Na verdade, a trajetória da bala possibilitando a lesão de múltiplos órgãos, assim como a liberação de estilhaços, entre outros fatores, poderiam ocasionar agraves mais críticos do que os decorrentes de lesões por arma branca.

No que se refere ao tempo de permanência, observou-se que a maioria da população ferida por armas $(53,5 \%)$ permanece internada nesse PS até 5 dias. 
Contudo, 46,5\% deles estiveram internados mais de 6 dias, caracterizando a especificidade deste serviço.

É relevante acrescentar que as associações entre tempo de permanência e evolução com as variáveis idade e sexo não configuram relações significativas, ou seja, não demonstram efeitos determinantes entre si.

\section{CONSIDERAC̣ÕES FINAIS}

A violência é uma realidade histórica, mas na nossa sociedade tem adquirido maiores dimensões além de continuar ampliando o seu leque de possibilidades. Ela pode ser considerada como inerente à condição humana ou como conseqüência do desequilíbrio das condições sócio-econômicas, política e cultural do meio.

Como qualquer outra forma de relação humana é gerida e mantida pelo poder social e econômico que estratifica formas de violência permissíveis ou não, além de estabelecer padrões de julgamento e aceitação. Nesse sentido, a violência decorrente do abuso de poder econômico e político, o monopólio de classes, gerando diferentes possibilidades de sobrevivência, entre outras, são menos perceptíveis.

As agressões evidenciadas neste estudo, em contrapartida, configuram quase que um estigma das classes menos favorecidas, sendo as que mais têm merecido a perseguição policial e a maior divulgação pelos meios de comunicação. Acredita-se, contudo, que apesar desse quadro constituir uma realidade aparentemente cristalizada, só haverá possibilidade de melhora à medida em que os problemas de base forem identificados e solucionados. Para tanto, talvez a efetivação de uma política de distribuição equitativa de condições de vida e trabalho, além de uma revisão dos valores inerentes ao relacionamento humano na sua essência é que possibilitariam a transformação desse contexto, independentes de medidas coercitivas e não resolutivas até então tomadas.

Outro aspecto a ser considerado relaciona-se ao impacto social decorrentes dessa violência. Um contingente de jovens, parte de uma força de trabalho, está sendo sistematicamente afastada do seu meio. Terá limitações, temporárias ou permanentes, decorrentes de agressão sof rida, representando um ônus à sua vida $\mathrm{e}$ à sociedade. Esse quadro configura um ciclo vicioso, à medida em que o indivíduo vítima de violência ao ser alijado do sistema produtivo pode constituir-se numa nova fonte de violência.
Outra distorção dessa mesma realidade social pode ser identificada na medida em que o sistema de saúde, intencionalmente já tão desprovido de recursos, passa, agora, a ter que absorver uma população atingida por doenças não naturais, acarretando a perpetuação de uma assistência hospitalar quase sempre não resolutiva.

Na verdade, vivemos uma época onde predomina a ideologia do medo, da segregação social e da descaracterização do aparato legal, viabilizando e mantendo a violência. Nesse contexto, caberia à equipe de saúde o compromisso não apenas assistencial como também no âmbito político, pois sómente a modificação dessa estrutura vigente é que poderia promover a justiça social, levando em seu bojo o espaço para uma nova forma de relacionamento humano.

\section{CONCLUSÕES}

Os resultados obtidos nesse estudo possibilitaram as seguintes conclusões:

- as formas de violência mais freqüentes foram as causadas por arma de fogo $(64,5 \%)$ e por arma branca23,6\%);

- a população mais atingida foi a masculina (92,3\%) e a faixa etária predominante, independente do sexo, foi a compreendida entre 16 e 45 anos $(69,8 \%)$;

- no que se refere à evolução das vítimas ocasionadas por armas de fogo e branca, verificou-se que a grande maioria (respectivamente $80,7 \%$ e $82,8 \%$ ) encontravem-se com prognóstico "em aberto". Observou-se, também, que os óbitos precoces assim como a cura mais tardia ocorreram mais entre os feridos por armas de fogo;

- a maioria da população ferida por armas permaneceu até 5 dias internada no PS $(53,5 \%)$.

\section{REFERÊNCIAS BIBLIOGRÁFICAS}

1. IDE, C.A.C. et alii. Perfil epidemiológico das internações de um Pronto Socorro do Município de São Paulo. 1986.

2. MENDES, D.C. Serviços de emergência - conceituação, normas e planejamento. Revista Paulista de Hospitais. 30(3/4): 65-70, mar/abr. 1982.

3. PETLUND. C.F. Epidemiologic investigations of stroke, Scand. J. Rehabil. Med., Stockholm, 7(suppl.): 11-4, aug. 1980. 